1 Identifying chain elongation processes during

\title{
the mixed-culture fermentation of proteins
}

\author{
R. Bevilacqua*, A. Regueira, J.M. Lema, M. Carballa, M. \\ Mauricio-Iglesias
}

* presenter, riccardo.bevilacqua@usc.es

CRETUS Institute, Department of Chemical Engineering, Universidade de Santiago de Compostela, Spain

\section{HIGHLIGHTS:}

- Chain elongation was identified for the first time as a relevant process occurring in protein mixed-culture fermentation

- No external electron donor compound is required for the VFA elongation from proteins

- Its feasibility depends on both the chosen $\mathrm{pH}$ setpoint and protein composition

BACKGROUND: the chain elongation processes occurring during the fermentation of carbohydrate-rich residual streams have already been thoroughly studied, with multiple example available in literature (Angenent et al., 2016). On the contrary, little is known on the role of proteins as substrates. The only previous studies focusing on amino acidbased chain elongation were performed with pure culture of a bacterium isolated from bovine rumen, Eubacterium pyruvativorans (Wallace et al., 2003), which consumes short chain VFAs to elongate butyric to caproic acid, using amino acids (e.g. alanine and leucine) as electron donor compounds (Wallace et al., 2004). Conversely, the feasibility of chain elongation process in mixed-culture microbiomes fermenting proteins has not been described before.

Hence, the aim of the present study was to verify the potential of proteins as a single substrate for the acidification and condensation of longer chain carboxylates while evaluating the related mechanisms and the required operational conditions.

METHODOLOGY: integrating the results of a previous study with two different proteins, casein and gelatin (Bevilacqua et al., 2020), two fermentation batch tests were performed at $\mathrm{pH} 5$ using casein as the sole carbon source. The chosen substrate-to-inoculum ratio (SIR) was of $20 \mathrm{~g}$ COD protein/g VSS, with macronutrients being added accordingly, while the results from the previous study were obtained with a SIR equal to 10 . Acetic acid was supplemented to one of the batch tests (approx. 10 $\mathrm{mmol} / \mathrm{L}$ ) to better understand the role of short chain carboxylates as electron acceptor compounds in protein-based chain elongation processes. 
RESULTS AND DISCUSSION: Both tests lasted 384 hours, leading to the final products spectra (mmol/L basis) observable in figure 1 . In both cases, the main products were n-butyric and iso-valeric acid (Fig. 1b), while $n$-valeric acid production depended on whether acetic acid was supplemented at the beginning of the batch operation.
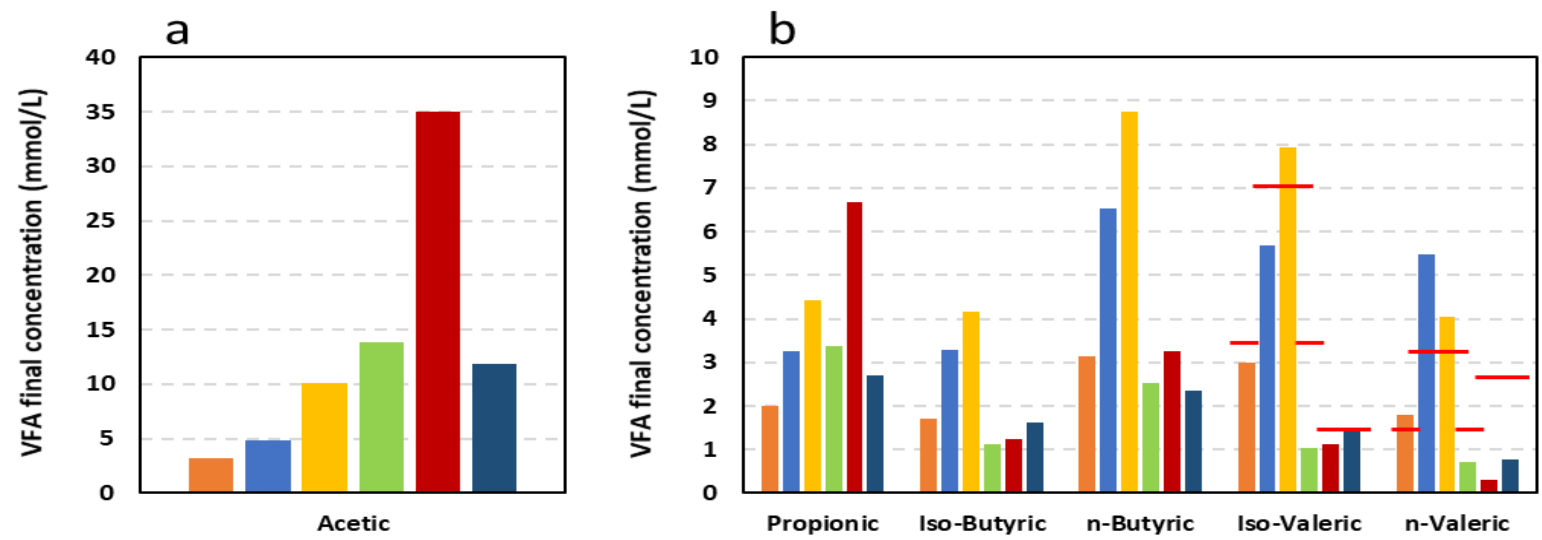

Figure 1. VFA final concentration obtained in batch fermentation tests performed with casein and gelatin at different $\mathrm{pH}$ values (a: acetic acid; $b$ : remaining VFAs). - Casein pH 5 SIR10; - Casein pH 5 SIR20; - Casein pH 5 SIR20 with acetic acid supplementation; - Casein pH 7 SIR10; - Gelatin pH 7 SIR10; - Gelatin pH 5 SIR10. The red horizontal bars illustrate the maximum theoretical production of iso and n-valeric acids based on the chosen substrate.

Consumption of acetic and propionic acid in the first stages (24-72 hours) of the casein batch tests was observed (concentration profile not shown here), suggesting the existence of chain elongation processes. Furthermore, no external electron donor supplementation was required, as amino acids probably reacted with in-situ produced VFAs. The acetic acid supplementation test helped identify the elongation process as the final concentration of this acid was comparable to the initial one. In fact, the 5 $\mathrm{mmol} / \mathrm{L}$ produced in the SIR 20 test plus the $10 \mathrm{mmol} / \mathrm{L}$ of acetic acid supplemented should have led to a total $15 \mathrm{mmol} / \mathrm{L}$ at the end of this test. As only $10 \mathrm{mmol} / \mathrm{L}$ were measured (Fig. 1a), it indicates that some 5 $\mathrm{mmol} / \mathrm{L}$ of may have been used for chain elongation. The acetic acid supplementation also increased the overall casein conversion and diverted the condensation towards iso-valeric acid and possibly n-butyric acid. Still, protein-based fermentation appears to be especially selective towards nvaleric acid as its production was always greater than theoretically possible by acidification only in both tests (Fig. 1b), given that this VFA only originates from a well identified amino acid, proline (Bevilacqua et al., 2020; Regueira et al., 2020). Comparing these results with the ones obtained from the fermentation of different proteins (Bevilacqua et al., 2020), it appears that protein composition and $\mathrm{pH}$ are fundamental in determining the feasibility of the chain elongation. The process was only identified during casein fermentation at low $\mathrm{pH}(5.0)$; gelatin did not undergo chain elongation during its anaerobic conversion to VFAs (Fig. 
1b). The relative abundance of amino acids acting as electron donors might explain the differences according to the substrate.

CONCLUSION: to the best of our knowledge, chain elongation was identified for the first time during mixed-culture fermentation of proteins. This kind of process is especially attractive as it does not require electron donor supplementation as in most cases described in literature. Also, its feasibility depends on the environmental conditions (i.e. low $\mathrm{pH}$ ) and the protein composition. This work helps to shed some light on amino acidbased chain elongation in mixed microbiomes while constituting a starting point for further studies on the subject.

\section{REFERENCES}

1. Angenent, L.T., Richter, H., Buckel, W., Spirito, C.M., Steinbusch, K.J.J., Plugge, C.M., Strik, D.P.B.T.P., Grootscholten, T.I.M., Buisman, C.J.N., Hamelers, H.V.M. Chain elongation with reactor microbiomes: open-culture biotechnology to produce biochemicals. Environ. Sci. Technol., 2016, 50, 2796-2810.

2. Bevilacqua, R., Regueira, A., Mauricio-Iglesias, M., Lema, J.M., Carballa, M. Steering the conversion of protein residues to short chain carboxylates by adjusting $\mathrm{pH}$. Submitted

3. Regueira, A., Lema, J.M., Carballa, M., Mauricio-Iglesias, M. Metabolic modeling for predicting VFA production from protein-rich substrates by mixed-culture fermentation. Biotechnology and Bioengineering, 2020, 117, 73-84.

4. Wallace, R. J., Chaudhary, L. C., Miyagawa, E., McKain, N., Walker, N. D. Metabolic properties of Eubacterium pyruvativorans, a ruminal, "hyper-ammonia-producing," anaerobe with metabolic properties analogous to those of Clostridium kluyveri. Microbiology, 2004, 150 (9) 2921- 2930.

5. Wallace, R. J., McKain, N., McEwan, N.R., Miyagawa, E., Chaudhary, L.C., King, T.P., Walker, N.D., Apajalahti, J.H.A., Newbold, C.J. Eubacterium pyruvativorans sp. nov., a novel non-saccharolytic anaerobe from the rumen that ferments pyruvate and amino acids, forms caproate and utilizes acetate and propionate. Microbiology, 2003, 53 (4), 965-970. 